\title{
Metastatic pancreatic adenocarcinomas could be classified into M1a and M1b category by the number of metastatic organs
}

Fang Feng ${ }^{1}$, Wei Cai ${ }^{2}$, Gaoming Wang ${ }^{2}$, Weigang Chen ${ }^{2}$, Haochang Yang ${ }^{3}$, Mingyu Sun ${ }^{4}$ and Li Zhou ${ }^{1 *}$

\begin{abstract}
Background: With the improvement of treatment and prognosis for patients with late malignant diseases, certain malignancies with distant metastasis (M1 category) have been further classified into M1a (single metastatic site) and M1b (multiple metastatic sites) category in the staging system. We aimed to assess the feasibility of sub-classifying metastatic pancreatic adenocarcinoma ( $\mathrm{mPA}$ ) into M1a and M1b category depending on the number of metastatic organs.
\end{abstract}

Methods: Patient records were collected from the Surveillance, Epidemiology, and End Results (SEER) database (2010-2015). Univariable and multivariable analyses were performed using the Cox regression model. Then survival analysis was determined using the Kaplan-Meier method.

Results: A total of 11,885 patients were included in this analysis, including 9425 patients with single metastasis and 2460 patients with multiple metastases. Multivariable analysis showed that gender, age, marital status, grade, surgery, chemotherapy, and radiotherapy were independent prognostic factors for patients with single metastasis; gender, age, marital status, grade, chemotherapy and radiotherapy were independent prognostic factors for patients with multiple metastases. Notably, surgery was an independent prognostic factor for patients with single metastasis $(P<0.001)$ but not for patients with multiple metastases $(P=0.134)$. Kaplan-Meier analysis showed that patients with single metastasis (M1a) had better survival outcomes than patients with multiple metastases (M1b) $(P<0.001)$.

Conclusions: PA patients with M1 diseases could be divided into M1a (single metastasis) category and M1b (multiple metastases) category by the number of metastatic organs. The subclassification would facilitate individualized treatment for late PA patients. Surgery was associated with lower mortality in M1a patients but not significantly in M1b patients.

Keywords: Metastatic pancreatic adenocarcinoma, SEER, Overall survival, AJCC

\footnotetext{
* Correspondence: 527829963@qq.com

'Department of Oncology, Suzhou Ninth People's Hospital, Suzhou 215200,

China

Full list of author information is available at the end of the article
}

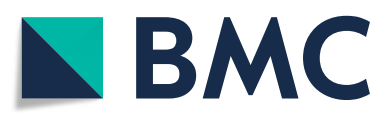

() The Author(s). 2020 Open Access This article is licensed under a Creative Commons Attribution 4.0 International License, which permits use, sharing, adaptation, distribution and reproduction in any medium or format, as long as you give appropriate credit to the original author(s) and the source, provide a link to the Creative Commons licence, and indicate if changes were made. The images or other third party material in this article are included in the article's Creative Commons licence, unless indicated otherwise in a credit line to the material. If material is not included in the article's Creative Commons licence and your intended use is not permitted by statutory regulation or exceeds the permitted use, you will need to obtain permission directly from the copyright holder. To view a copy of this licence, visit http://creativecommons.org/licenses/by/4.0/ The Creative Commons Public Domain Dedication waiver (http://creativecommons.org/publicdomain/zero/1.0/) applies to the data made available in this article, unless otherwise stated in a credit line to the data. 


\section{Background}

Pancreatic cancer (PC), the fourth leading cause of cancerrelated deaths in the United States, is a highly lethal and aggressive malignancy with a 5-year survival rate of less than $5 \%[1,2]$. Approximately half of PC patients have developed distant metastasis at the time of first diagnosis [3]. According to the current clinical guidelines for PC patients without distant metastasis, radical surgery together with chemotherapy is regarded as the primary treatment strategy although there are many borderline resectable and unresectable cases due to the location/local extension of the tumor. For metastatic PC patients (mPC), however, chemotherapy is recommended rather than surgery $[4,5]$. Since accumulating evidence has demonstrated that primary tumor resection is beneficial to patients with metastatic malignancies [6-9], some researchers have explored whether local therapy has a favorable impact on mPC survival. Tao et al .[3] reported that surgical resection of primary tumors could prolong survival times in patients with mPC. Crippa et al. [10] found that surgical resection of primary pancreatic tumor was related to improved survival for mPC patients undergoing chemotherapy. These findings broadened the clinical perspective on surgical treatment for $\mathrm{mPC}$.

With the improvement of treatment and prognosis for patients with late malignant diseases, certain malignancies with distant metastasis (M1 category) will be further classified into M1a (single metastatic site) and M1b (multiple metastatic sites) category in the staging system. For instance, M1 colorectal cancer (CRC) was further classified into M1a and M1b category in the 7th edition of American Joint Committee on Cancer (AJCC) staging manual [11]. M1 lung cancer was divided into M1a and M1b category in the International Association for the Study of Lung Cancer (IASLC) Staging Project [12]. It has not been investigated whether $\mathrm{MPC}$ patients should be further classified into subgroups yet. Hani et al. [13] reported that the number of metastatic organs was not significantly associated with the prognosis of MPC patients using the Surveillance Epidemiology and End Results (SEER) database. However, the result may be caused by their inappropriate inclusion criteria. The primary tumor of their study cohort should be restricted to "first sequence" rather than "two or larger sequence". Some PA patients with a history of other malignancies would be included by the inappropriate inclusion criteria, which may lead to selection bias. Therefore, we aimed to assess the feasibility of sub-classifying metastatic pancreatic adenocarcinoma (mPA) into M1a and M1b category depending on the number of metastatic organs.

\section{Methods}

\section{Patients}

Data on patients with pancreatic adenocarcinomas were extracted from the SEER database, which is one of the largest clinical databases covering $\sim 26 \%$ of the population in the United States [14]. Tumor site was coded as pancreas according to the International Classification of Diseases for Oncology (3rd edition, ICD-O-3). The further inclusion criteria were: (1) diagnosed between 2010 and 2015; (2) 18 years or older; (3) first primary tumor; (4) adenocarcinomas with positive histology; (5) distant metastasis with definite metastatic sites (liver, lung, bone and brain); (6) active follow-up information. Patients with distant metastasis (other organs rather than bone, liver, lung or brain) were excluded because they were not able to be assessed accurately based on the SEER data. Baseline patient characteristics included gender, age, race/ethnicity, tumor location, marital status, grade, tumor size, chemotherapy, radiotherapy, surgery and survival time. Follow-up time ranged from 0 to 70 months with a mean follow-up time of 5.7 months. The number of events for overall survival (OS) was 10,306 during the follow-up period.

\section{Statistical analysis}

The factors associated with prognosis were determined by univariable and multivariable analyses using the Cox regression model and the proportional of hazards assumption was verified using Schoenfeld residuals. Kaplan-Meier analyses were used to evaluate the OS. All statistical analyses were performed using PASW Statistics 18 . A two-sided $P$-value $<0.05$ was considered statistically significant.

\section{Results}

\section{Patient characteristics}

A total of 11,885 patients with mPA met our inclusion criteria consisting of 9425 patients with single metastasis and 2460 patients with multiple metastases (Table 1). The entire cohort included 6564 male and 5321 female patients with a median age of 66 years (ranging from 19 to 100). Patients with tumors located in the body/tail of pancreas had a larger proportion (37.1\%) than those in the head of pancreas (33.4\%). Most patients were White (9362, 78.8\%) and more than half $(6634,55.8 \%)$ were married. The proportion of patients with poorly differentiated or undifferentiated tumors was barely larger than those with well or moderately differentiated tumors. The majority of patients received chemotherapy (55.0\%), followed by radiotherapy (5.2\%) and surgery (4.6\%).

\section{Factors associated with the prognosis}

Using the Cox regression model, univariable and multivariable survival analyses were performed (Tables 2 and 3). Multivariable analysis showed that gender, age $(\leq 65 \mathrm{yrs}$. vs. $>65$ yrs), marital status (married vs. unmarried/unknown), grade (well/moderately differentiated vs. poorly differentiated/undifferentiated), surgery (no vs. yes), 
Table 1 Clinopathologic characteristics of mPA patients

\begin{tabular}{|c|c|c|c|c|}
\hline Variables & Total $(\boldsymbol{n}=11,885)$ & Single Metastasis $(\boldsymbol{n}=9425)$ & Multiple Metastases $(\boldsymbol{n}=2460)$ & $\boldsymbol{P}$ value \\
\hline Gender & & & & 0.089 \\
\hline Male & $6564(55.2 \%)$ & $5168(54.8 \%)$ & $1396(56.7 \%)$ & 0.089 \\
\hline Female & $5321(44.8 \%)$ & $4257(45.2 \%)$ & $1064(43.3 \%)$ & \\
\hline Age (years) & & & & 0.174 \\
\hline$\leq 65$ & $5725(48.2 \%)$ & $4570(48.5 \%)$ & 1155 (47.0\%) & \\
\hline$>65$ & $6160(51.8 \%)$ & 4855 (51.5\%) & $1305(53.0 \%)$ & \\
\hline Range (median) & 19-100 (66) & 19-100 (66) & $21-96(66)$ & \\
\hline Race & & & & 0.434 \\
\hline White & $9362(78.8 \%)$ & 7427 (78.8\%) & 1935 (78.7\%) & \\
\hline Black & $1622(13.6 \%)$ & $1297(13.8 \%)$ & $325(13.2 \%)$ & \\
\hline Others & $901(7.6 \%)$ & $701(7.4 \%)$ & $200(8.1 \%)$ & \\
\hline Tumor location & & & & $<0.001$ \\
\hline Head & 3972 (33.4\%) & 3371 (35.8\%) & $601(24.4 \%)$ & \\
\hline Body/tail & 4409 (37.1\%) & 3405 (36.1\%) & $1004(40.8 \%)$ & \\
\hline Others & 3504 (29.5\%) & 2649 (28.1\%) & $855(34.8 \%)$ & \\
\hline Marital status & & & & 0.549 \\
\hline Married & $6634(55.8 \%)$ & $5274(56.0 \%)$ & $1360(55.3 \%)$ & \\
\hline Unmarried/unknown & $5251(44.2 \%)$ & $4151(44.0 \%)$ & $1100(44.7 \%)$ & \\
\hline Grade & & & & 0.001 \\
\hline Well/moderately differentiated & $1308(11.0 \%)$ & $1089(11.5 \%)$ & 219 (8.9\%) & \\
\hline Poorly differentiated/undifferentiated & $1439(12.1 \%)$ & $1148(12.2 \%)$ & $291(11.8 \%)$ & \\
\hline Unknown & $9138(76.9 \%)$ & $7188(76.3 \%)$ & $1950(79.3 \%)$ & \\
\hline \multicolumn{5}{|l|}{ Tumor size $(\mathrm{mm})^{*}$} \\
\hline Range (median) & $0-950(40)$ & $0-900(40)$ & $0-950(43)$ & \\
\hline Surgery & & & & $<0.001$ \\
\hline No & $11,335(95.4 \%)$ & $8948(94.9 \%)$ & 2387 (97.0\%) & \\
\hline Yes & $550(4.6 \%)$ & $477(5.1 \%)$ & $73(3.0 \%)$ & \\
\hline Chemotherapy & & & & 0.013 \\
\hline No/unknown & $5350(45.0 \%)$ & $4188(44.4 \%)$ & $1162(47.2 \%)$ & \\
\hline Yes & $6535(55.0 \%)$ & $5237(55.6 \%)$ & $1298(52.8 \%)$ & \\
\hline Radiotherapy & & & & $<0.001$ \\
\hline No & $11,270(94.8 \%)$ & 9061 (96.1\%) & 2209 (89.8\%) & \\
\hline Yes & $615(5.2 \%)$ & $364(3.9 \%)$ & $251(10.2 \%)$ & \\
\hline Metastatic sites & & & & $<0.001$ \\
\hline Bone & 1056 & 193 & 863 & \\
\hline Brain & 111 & 21 & 90 & \\
\hline Liver & 10,883 & 8523 & 2360 & \\
\hline lung & 2678 & 688 & 1990 & \\
\hline * 2723 cases missing. & & & & \\
\hline
\end{tabular}

chemotherapy (no vs. yes) and radiotherapy (no vs. yes) were independent prognostic factors for patients with single metastasis; gender, age ( $\leq 65 \mathrm{yrs}$. vs. $>65 \mathrm{yrs}$ ), marital status (married vs. unmarried/unknown), grade (well/ moderately differentiated vs. poorly differentiated/ undifferentiated), chemotherapy (no vs. yes) and radiotherapy (no vs. yes) were independent prognostic factors for patients with multiple metastases. Notably, surgery was an independent prognostic factor for patients with single metastasis $(P<0.001)$ but not for patients with 
Table 2 Univariable analysis for mPA patients

\begin{tabular}{|c|c|c|c|c|}
\hline \multirow[t]{2}{*}{ Variables } & \multicolumn{2}{|l|}{$\begin{array}{l}\text { Single Metastasis } \\
(\boldsymbol{n}=9425)^{\boldsymbol{c}}\end{array}$} & \multicolumn{2}{|l|}{$\begin{array}{l}\text { Multiple Metastases } \\
(\boldsymbol{n}=2460)^{\mathbf{c}}\end{array}$} \\
\hline & $\mathrm{HR}^{\mathbf{a}}\left(95 \% \mathrm{Cl}^{\mathbf{b}}\right)$ & $\overline{P \text { value }}$ & $\overline{\mathrm{HR}(95 \% \mathrm{Cl})}$ & $\overline{P \text { value }}$ \\
\hline \multicolumn{5}{|l|}{ Gender } \\
\hline Male & Reference & & Reference & \\
\hline Female & $0.938(0.898-0.980)$ & 0.004 & $0.931(0.856-1.013)$ & 0.095 \\
\hline \multicolumn{5}{|l|}{ Age (years) } \\
\hline$\leq 65$ & Reference & & Reference & \\
\hline$>65$ & $1.460(1.397-1.526)$ & $<0.001$ & $1.344(1.235-1.461)$ & $<0.001$ \\
\hline \multicolumn{5}{|l|}{ Race } \\
\hline White & Reference & & Reference & \\
\hline Black & $1.075(1.009-1.145)$ & 0.026 & $1.007(0.890-1.140)$ & 0.907 \\
\hline Others & $0.981(0.902-1.067)$ & 0.655 & $1.053(0.904-1.227)$ & 0.505 \\
\hline \multicolumn{5}{|l|}{ Tumor location } \\
\hline Head & Reference & & Reference & \\
\hline Body/tail & $1.013(0.962-1.067)$ & 0.627 & $1.014(0.912-1.128)$ & 0.795 \\
\hline Others & $1.138(1.077-1.202)$ & $<0.001$ & $1.093(0.980-1.220)$ & 0.112 \\
\hline \multicolumn{5}{|l|}{ Marital status } \\
\hline Married & Reference & & Reference & \\
\hline Unmarried/unknown & $1.231(1.178-1.286)$ & $<0.001$ & $1.246(1.146-1.355)$ & $<0.001$ \\
\hline \multicolumn{5}{|l|}{ Grade } \\
\hline Well/moderately differentiated & Reference & & Reference & \\
\hline Poorly differentiated/undifferentiated & $1.718(1.566-1.884)$ & $<0.001$ & $1.531(1.273-1.840)$ & $<0.001$ \\
\hline Unknown & $1.630(1.515-1.753)$ & $<0.001$ & $1.411(1.216-1.637)$ & $<0.001$ \\
\hline Tumor size & $1.000(0.999-1.001)$ & 0.767 & $1.000(0.999-1.001)$ & 0.426 \\
\hline \multicolumn{5}{|l|}{ Surgery } \\
\hline No & Reference & & Reference & \\
\hline Yes & $0.513(0.461-0.572)$ & $<0.001$ & $0.749(0.584-0.961)$ & 0.023 \\
\hline \multicolumn{5}{|l|}{ Chemotherapy } \\
\hline No & Reference & & Reference & \\
\hline Yes & $0.432(0.413-0.452)$ & $<0.001$ & $0.350(0.320-0.382)$ & $<0.001$ \\
\hline \multicolumn{5}{|l|}{ Radiotherapy } \\
\hline No & Reference & & Reference & \\
\hline Yes & $0.737(0.657-0.827)$ & $<0.001$ & $0.729(0.635-0.838)$ & $<0.001$ \\
\hline
\end{tabular}

${ }^{\mathrm{a}} \mathrm{HR}$ hazard ratio

${ }^{\mathrm{b}} \mathrm{Cl}$ confidence interval

'The number of events for patients with single metastasis and multiple metastases were 8077 and 2229 , respectively

multiple metastases $(P=0.134)$. Kaplan-Meier analysis showed that patients with single metastasis (M1a) had better survival outcomes than those with multiple metastases (M1b) $(P<0.001$, Fig. 1a). To reduce possible bias caused by potential confounding factors, a 1:1 propensity score matching (PSM) was performed. After PSM, 4874 patients (2437 patients each for M1a and M1b groups) were included. Similar results were observed $(P<0.001$, Fig. 1 b). Among M1a patients with PA, surgery predicted better survival outcomes $(P<0.001$, Fig. 1c). After PSM, 950 patients (475 patients each for surgery and non- surgical groups) were included, and patients with surgery still had better survival outcomes $(P<0.001$, Fig. 1d).

Additionally, the effect of tumor location (head vs. body/tail) on the prognosis was further analyzed. Both patients with pancreatic head adenocarcinoma and those with pancreatic body/tail adenocarcinoma could benefit from surgery, and patients with pancreatic body/tail adenocarcinoma may benefit more $(P<$ 0.001, Fig. 1e and f). 
Table 3 Multivariable analysis for patients with metastatic pancreatic adenocarcinomas

\begin{tabular}{|c|c|c|c|c|}
\hline \multirow[t]{2}{*}{ Variables } & \multicolumn{2}{|l|}{$\begin{array}{l}\text { Single Metastasis } \\
(\boldsymbol{n}=9425)^{\boldsymbol{c}}\end{array}$} & \multicolumn{2}{|l|}{$\begin{array}{l}\text { Multiple Metastases } \\
(\boldsymbol{n}=2460)^{\mathbf{c}}\end{array}$} \\
\hline & $\mathrm{HR}^{\mathbf{a}}\left(95 \% \mathrm{Cl}^{\mathbf{b}}\right)$ & $\boldsymbol{P}$ value & $\mathrm{HR}(95 \% \mathrm{Cl})$ & $P$ value \\
\hline \multicolumn{5}{|l|}{ Gender } \\
\hline Male & Reference & & Reference & \\
\hline Female & $0.889(0.844-0.936)$ & $<0.001$ & $0.869(0.786-0.961)$ & 0.006 \\
\hline \multicolumn{5}{|l|}{ Age (years) } \\
\hline$\leq 65$ & Reference & & Reference & \\
\hline$>65$ & $1.333(1.267-1.403)$ & $<0.001$ & $1.259(1.139-1.391)$ & $<0.001$ \\
\hline \multicolumn{5}{|l|}{ Race } \\
\hline White & Reference & & Reference & \\
\hline Black & $1.058(0.983-1.140)$ & 0.132 & $0.984(0.845-1.145)$ & 0.834 \\
\hline Others & $0.969(0.879-1.069)$ & 0.529 & $1.073(0.895-1.286)$ & 0.447 \\
\hline \multicolumn{5}{|l|}{ Tumor location } \\
\hline Head & Reference & & Reference & \\
\hline Body/tail & $1.053(0.995-1.114)$ & 0.073 & $1.041(0.924-1.172)$ & 0.510 \\
\hline Others & $1.076(1.005-1.152)$ & 0.036 & $1.045(0.911-1.199)$ & 0.530 \\
\hline \multicolumn{5}{|l|}{ Marital status } \\
\hline Married & Reference & & Reference & \\
\hline Unmarried/unknown & $1.164(1.104-1.226)$ & $<0.001$ & $1.147(1.036-1.270)$ & 0.008 \\
\hline \multicolumn{5}{|l|}{ Grade } \\
\hline Well/moderately differentiated & Reference & & Reference & \\
\hline Poorly differentiated/undifferentiated & $1.952(1.757-2.169)$ & $<0.001$ & $1.522(1.218-1.901)$ & $<0.001$ \\
\hline Unknown & $1.781(1.637-1.937)$ & $<0.001$ & $1.440(1.201-1.726)$ & $<0.001$ \\
\hline Tumor size & $1.001(1.000-1.002)$ & 0.156 & $1.000(0.998-1.001)$ & 0.490 \\
\hline \multicolumn{5}{|l|}{ Surgery } \\
\hline No & Reference & & Reference & \\
\hline Yes & $0.460(0.405-0.522)$ & $<0.001$ & $0.773(0.551-1.083)$ & 0.134 \\
\hline \multicolumn{5}{|l|}{ Chemotherapy } \\
\hline No & Reference & & Reference & \\
\hline Yes & $0.428(0.406-0.451)$ & $<0.001$ & $0.360(0.324-0.401)$ & $<0.001$ \\
\hline \multicolumn{5}{|l|}{ Radiotherapy } \\
\hline No & Reference & & Reference & \\
\hline Yes & $0.819(0.719-0.932)$ & 0.003 & $0.799(0.673-0.948)$ & 0.010 \\
\hline
\end{tabular}

\section{Discussion}

The prognosis of PA patients is rather poor and numerous attempts have been made to improve the present clinical situation. In the current study, we showed that PA patients with M1 diseases could be divided into M1a (single metastasis) category and M1b (multiple metastases) category by the number of metastatic organs. Surgery was an independent prognostic factor for M1a patients. However, similar but not significant survival benefit tendency was also observed in M1b patients with surgery. To our best knowledge, this is the first time to propose a subclassification of PA patients with distant metastasis. The subclassification would facilitate individualized treatment for late PA patients.

Chemotherapy was recommended for $\mathrm{mPC}$ patients in the clinical practice guidelines [15]. However, the slow development of new chemotherapeutic agents seriously restrained the improvement of long-term survival in $\mathrm{mPC}$ patients. During the past decades, most chemotherapy regimens have always been based on 5-fluorouracil and 
A

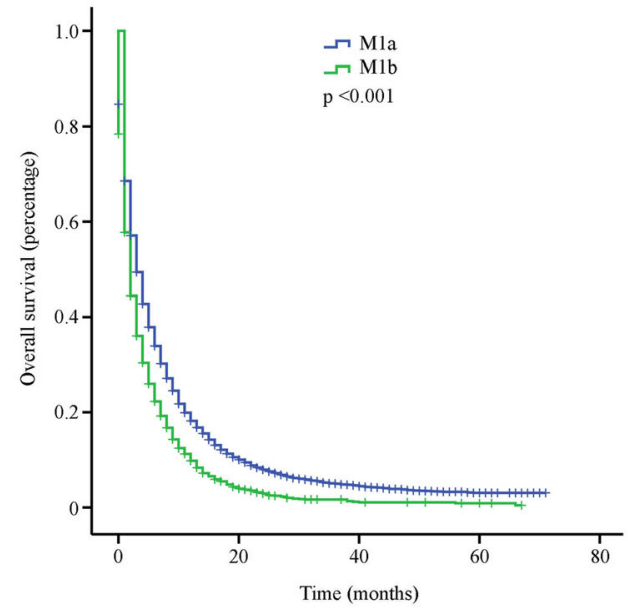

C

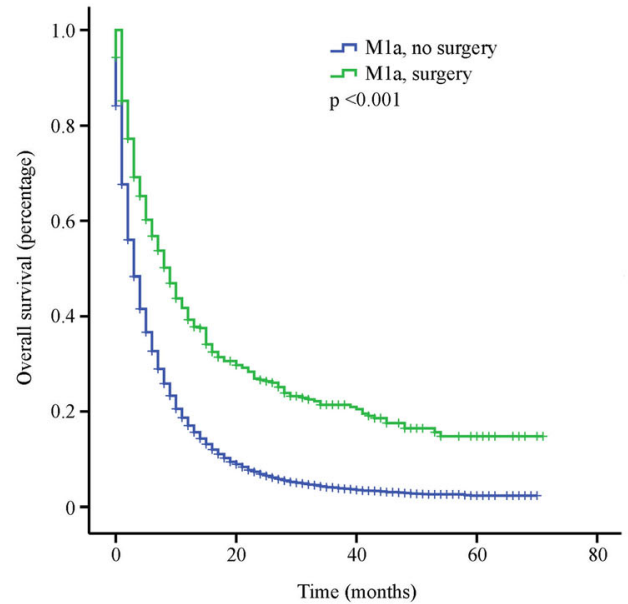

E

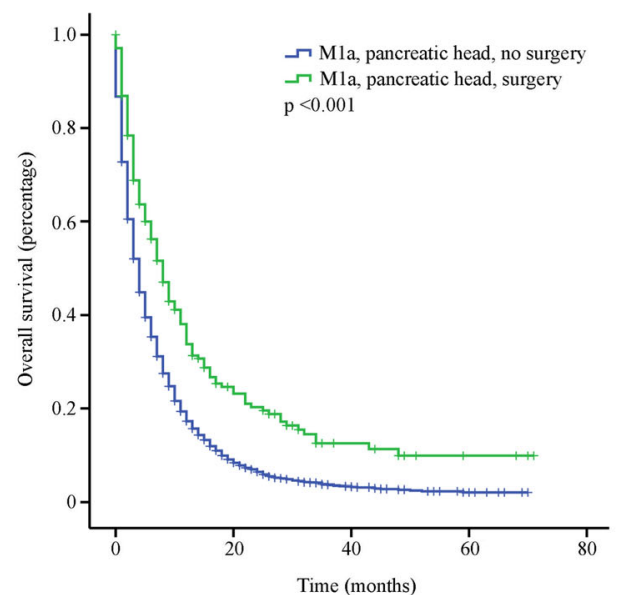

B

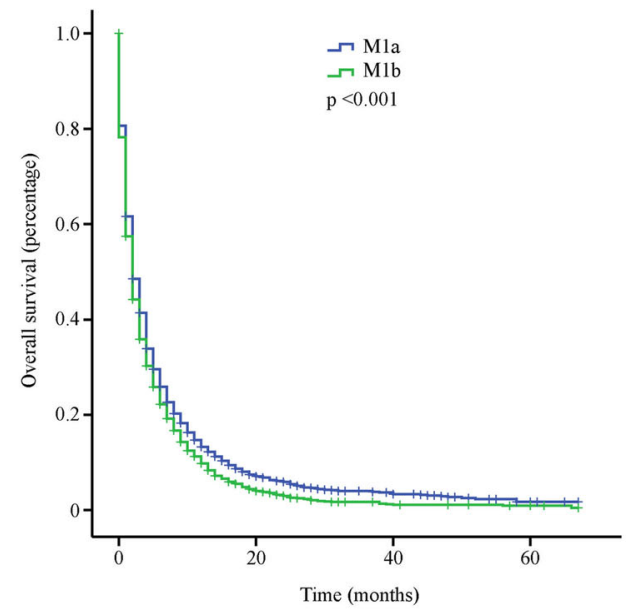

D

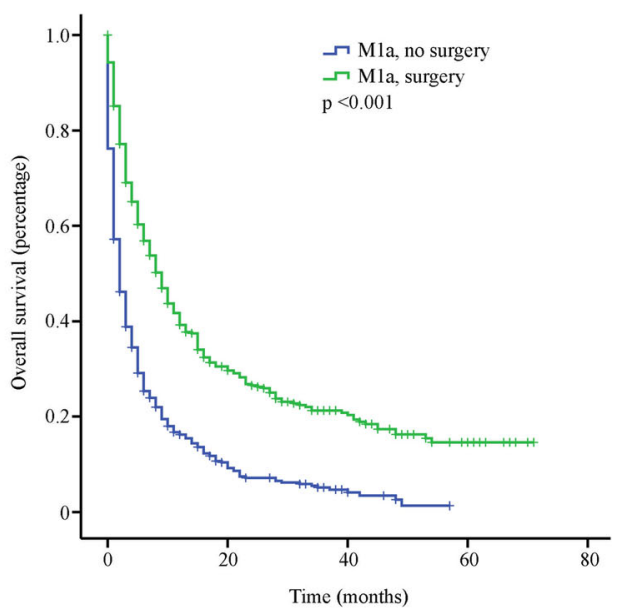

F

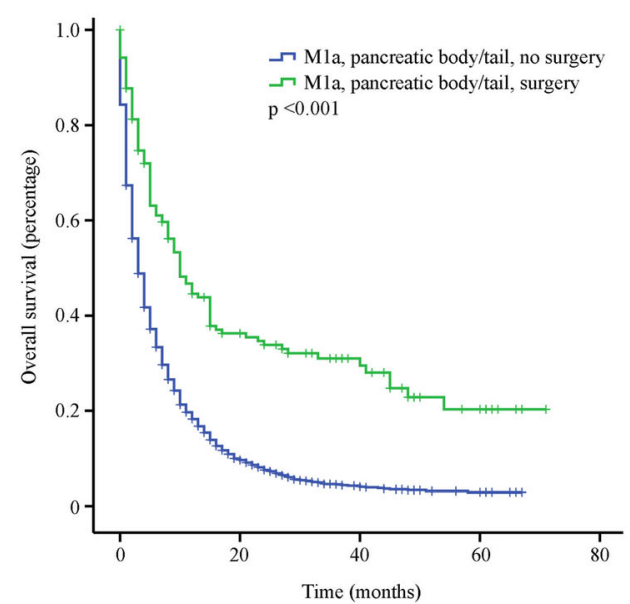

Fig. 1 Graphs of overall survival (OS). a Entire cohort stratified by the number of metastatic organs: M1a (single metastatic site) and M1 b (multiple metastatic sites). $\mathbf{b}$ Entire cohort after PSM. c M1a patients stratified by surgery. $\mathbf{d}$ M1a patients after PSM. e M1a patients with pancreatic head adenocarcinoma stratified by surgery. $\mathbf{f} \mathrm{Mla}$ patients with pancreatic body/tail adenocarcinoma stratified by surgery 
gemcitabine [16]. The emergence of molecule-targeted drugs did not even bring encouraging clinical benefits [17-19]. In this setting, more treatment options should be explored.

Surgery was considered as the best potential curative treatment for PC patients without distant metastasis but not indicated for $\mathrm{mPC}$ patients owing to its low safety and efficacy. With the remarkable progress of surgical techniques and procedures, extended surgical approaches can also be performed with low morbidity and mortality rates in well-selected $\mathrm{mPC}$ patients [20]. A SEER-based respective study showed that primary tumor resection could prolong the long-term survival of $\mathrm{mPC}$ patients [21]. However, they did not divided mPC patients into subgroups further according to metastatic sites. In our analysis, MPA patients with multiple metastases could not benefit from surgical treatment. In review of $23 \mathrm{mPC}$ patients, Dünschede et al. [22] reported that surgery may improve survival for patients with metachronous liver metastases but not for those with synchronous liver metastases. Another study consisting of 22 cases also showed that simultaneous resection of primary tumor and liver metastases would not result in favorable survival outcomes [23]. These inconsistent results may be caused by small samples. More prospective and randomized clinical trials should be designed for $\mathrm{mPC}$ patients with M1a diseases to estimate the efficacy of surgery. Unfortunately, surgical treatment seemed not appropriate for $\mathrm{mPC}$ patients with M1b diseases, possibly owing to extremely high degree of malignancy and wide range of metastases.

There are some limitations in the present study that should be noted. First, all patient data are retrospective. Second, neoadjuvant chemotherapy and postoperative therapy were not distinguished in the SEER database. Neoadjuvant chemotherapy presents a potential opportunity for cure for patients with borderline resectable pancreatic cancer but remains rarely used for patients with metastatic pancreatic cancer. Presumably, less than $5 \%$ of entire cohort received neoadjuvant chemotherapy in our study since only $4.6 \%$ received surgical treatment. For patients with metastatic pancreatic cancer, systemic adjuvant therapies are the mainstay of treatment. Chemotherapy regimens were not provided either in the SEER database. The heterogeneity of chemotherapy regimens may create a bias in our findings. Third, there are no validation cohorts from other databases. Nevertheless, these findings provide novel insights for the clinical management of $\mathrm{mPC}$ patients.

\section{Conclusion}

In sum, PA patients with M1 diseases could be divided into M1a (single metastasis) category and M1b (multiple metastases) category by the number of metastatic organs.
The subclassification would facilitate individualized treatment for late PA patients. Surgery was associated with lower mortality in M1a patients but not significantly in M1b patients.

\section{Abbreviations}

PC: Pancreatic cancer; mPA: Metastatic pancreatic adenocarcinoma;

SEER: Surveillance, Epidemiology, and End Results; CRC: Colorectal cancer;

AJCC: American Joint Committee on Cancer; IASLC: International Association for the Study of Lung Cancer; PSM: Propensity score matching; OS: Overall survival

\section{Acknowledgements}

Not applicable.

\section{Authors' contributions}

FF, LZ, and WC designed the study, carried out the analysis, and interpreted the data. GMW and WGC contributed to the review of previous literature. $\mathrm{HCY}$ and MYS contributed substantially to the data discussion and critically commented on the manuscript for scientific content. All authors have read and approved the manuscript.

Funding

No funding was received for this study.

Availability of data and materials

The datasets generated and analyzed during the current study are available from the corresponding author on reasonable request.

Ethics approval and consent to participate

The study protocol was approved by the Ethics Committee of Suzhou Ninth People's Hospital. All patients from the SEER database gave consent to participate in any scientific researches.

Consent for publication

Not applicable.

Competing interests

The authors declare that they have no competing interests.

\section{Author details}

${ }^{1}$ Department of Oncology, Suzhou Ninth People's Hospital, Suzhou 215200 China. ${ }^{2}$ Department of Thoracic Surgery, Xuzhou Central Hospital, The Affiliated Xuzhou Hospital of Medical College of Southeast University, Xuzhou 221009, China. ${ }^{3}$ College of Clinical Medicine, Binzhou Medical University, Yantai 264003, China. ${ }^{4}$ Department of Breast Surgery, Xuzhou Central Hospital, The Affiliated Xuzhou Hospital of Medical College of Southeast University, Xuzhou 221009, China.

Received: 7 June 2020 Accepted: 20 August 2020

Published online: 27 August 2020

\section{References}

1. Siegel RL, Miller KD, Jemal A. Cancer statistics, 2017. CA Cancer J Clin. 2017; 67(1):7-30.

2. Yang Y, Wang Y, Liu S, Zhao X, Jia R, Xiao Y, Zhang M, Li X, Li J, Wang W. How hsa-miR-495 performed in the tumorigenesis of pancreatic adenocarcinoma by bioinformatics analysis. J Cell Biochem. 2018.

3. Tao L, Yuan C, Ma Z, Jiang B, Xiu D. Surgical resection of a primary tumor improves survival of metastatic pancreatic cancer: a population-based study. Cancer Manag Res. 2017:9:471-9.

4. Kamisawa T, Wood LD, Itoi T, Takaori K. Pancreatic cancer. Lancet. 2016: 388(10039):73-85.

5. Sohal DP, Mangu PB, Khorana AA, Shah MA, Philip PA, O'Reilly EM, Uronis $\mathrm{HE}$, Ramanathan RK, Crane CH, Engebretson A, et al. Metastatic pancreatic Cancer: American Society of Clinical Oncology clinical practice guideline. J Clin Oncol. 2016:34(23):2784-96.

6. Flanigan RC, Salmon SE, Blumenstein BA, Bearman SI, Roy V, McGrath PC, Caton JR Jr, Munshi N, Crawford ED. Nephrectomy followed by interferon 
alfa- $2 \mathrm{~b}$ compared with interferon alfa-2b alone for metastatic renal-cell cancer. N Engl J Med. 2001;345(23):1655-9.

7. Temple LK, Hsieh L, Wong WD, Saltz L, Schrag D. Use of surgery among elderly patients with stage IV colorectal cancer. J Clin Oncol. 2004;22(17):3475-84.

8. Fossati N, Trinh QD, Sammon J, Sood A, Larcher A, Sun M, Karakiewicz P, Guazzoni G, Montorsi F, Briganti A, et al. Identifying optimal candidates for local treatment of the primary tumor among patients diagnosed with metastatic prostate cancer: a SEER-based study. Eur Urol. 2015;67(1):3-6.

9. Culp SH, Schellhammer PF, Williams MB. Might men diagnosed with metastatic prostate cancer benefit from definitive treatment of the primary tumor? A SEER-based study. Eur Urol. 2014;65(6):1058-66.

10. Crippa S, Bittoni A, Sebastiani E, Partelli S, Zanon S, Lanese A, Andrikou K, Muffatti $F$, Balzano $G$, Reni $M$, et al. Is there a role for surgical resection in patients with pancreatic cancer with liver metastases responding to chemotherapy? Eur J Surg Oncol. 2016:42(10):1533-9.

11. Washington K. 7th edition of the AJCC cancer staging manual: stomach. Ann Surg Oncol. 2010;17(12):3077-9.

12. Groome PA, Bolejack V, Crowley JJ, Kennedy C, Krasnik M, Sobin LH, Goldstraw P, Committee IIS, Cancer R, Biostatistics, et al. The IASLC lung Cancer staging project: validation of the proposals for revision of the T, N, and $\mathrm{M}$ descriptors and consequent stage groupings in the forthcoming (seventh) edition of the TNM classification of malignant tumours. J Thorac Oncol. 2007;2(8):694-705.

13. Oweira H, Petrausch U, Helbling D, Schmidt J, Mannhart M, Mehrabi A Schob O, Giryes A, Decker M, Abdel-Rahman O. Prognostic value of sitespecific metastases in pancreatic adenocarcinoma: a surveillance epidemiology and end results database analysis. World I Gastroenterol. 2017;23(10):1872-80.

14. Gillespie L. Dr. Gillespie, on the bites of serpents. Med Phys J. 1800;4(20):293-5.

15. Tempero MA, Malafa MP, Al-Hawary M, Asbun H, Bain A, Behrman SW Benson AB 3rd, Binder E, Cardin DB, Cha C, et al. Pancreatic adenocarcinoma, version 2.2017, NCCN clinical practice guidelines in oncology. J Natl Compr Cancer Netw. 2017;15(8):1028-61.

16. Oneda E, Zaniboni A. Are We Sure that Adjuvant Chemotherapy is the Best Approach for Resectable Pancreatic Cancer? Are We in the Era of Neoadjuvant Treatment? A Review of Current Literature. J Clin Med. 2019;8(11).

17. Philip PA, Benedetti J, Corless CL, Wong R, O'Reilly EM, Flynn PJ, Rowland KM, Atkins JN, Mirtsching BC, Rivkin SE, et al. Phase III study comparing gemcitabine plus cetuximab versus gemcitabine in patients with advanced pancreatic adenocarcinoma: southwest oncology group-directed intergroup trial S0205. J Clin Oncol. 2010;28(22):3605-10.

18. Kindler HL, Niedzwiecki D, Hollis D, Sutherland S, Schrag D, Hurwitz H, Innocenti F, Mulcahy MF, O'Reilly E, Wozniak TF, et al. Gemcitabine plus bevacizumab compared with gemcitabine plus placebo in patients with advanced pancreatic cancer: phase III trial of the Cancer and leukemia group B (CALGB 80303). J Clin Oncol. 2010;28(22):3617-22.

19. Kindler HL, loka T, Richel DJ, Bennouna J, Letourneau R, Okusaka T, Funakoshi A, Furuse J, Park YS, Ohkawa S, et al. Axitinib plus gemcitabine versus placebo plus gemcitabine in patients with advanced pancreatic adenocarcinoma: a double-blind randomised phase 3 study. Lancet Oncol. 2011;12(3):256-62.

20. Hackert T, Buchler MW. Pancreatic cancer: advances in treatment, results and limitations. Dig Dis. 2013;31(1):51-6.

21. Wang $L$, Yang $L$, Chen $L$, Chen $Z$. Do patients diagnosed with metastatic pancreatic Cancer benefit from primary tumor surgery? A propensityadjusted, population-based surveillance, epidemiology and end results (SEER) analysis. Med Sci Monit. 2019;25:8230-41.

22. Dunschede F, Will L, von Langsdorf C, Mohler M, Galle PR, Otto G, Vahl CF, Junginger $\mathrm{T}$. Treatment of metachronous and simultaneous liver metastases of pancreatic cancer. Eur Surg Res. 2010;44(3-4):209-13.

23. Gleisner AL, Assumpcao L, Cameron JL, Wolfgang CL, Choti MA, Herman JM, Schulick RD, Pawlik TM. Is resection of periampullary or pancreatic adenocarcinoma with synchronous hepatic metastasis justified? Cancer. 2007;110(11):2484-92.

\section{Publisher's Note}

Springer Nature remains neutral with regard to jurisdictional claims in published maps and institutional affiliations.

\section{Ready to submit your research? Choose BMC and benefit from}

- fast, convenient online submission

- thorough peer review by experienced researchers in your field

- rapid publication on acceptance

- support for research data, including large and complex data types

- gold Open Access which fosters wider collaboration and increased citations

- maximum visibility for your research: over $100 \mathrm{M}$ website views per year

At $\mathrm{BMC}$, research is always in progress.

Learn more biomedcentral.com/submissions 